\title{
Managing Global Teams
}

\author{
Anca Ştefania Stan, „Vasile Alecsandri” University of Bacau, Romania
}

\begin{abstract}
Every global company's competitive advantage depends on its ability to coordinate critical resources and information that are spread across different geographical locations. As a result of the increasingly global business environment, many companies are building teams that cross- national borders and / or include members from different countries of origin. Global teams are formed to enhance the efficiency of an organization by making effective use of the diversity or viewpoints.
\end{abstract}

\section{Keywords}

Teams, Global Teams, Cultural Diversity, Globalization, Multicultural Teams,

\section{Jel Codes: M 14, M 16}

With the inception of globalization transition is witnessed in almost all concerns of businesses. Organizations are addressing the challenges of globalization by undertaking a reconsideration of their traditional ways of functioning. As a result of the increasingly global business environment, many companies are building teams that cross- national borders and / or include members from different countries of origin. Individuals from different racial and ethnic backgrounds will need to work together in a local workplace, a multinational corporation or an international organization. Although many of these teams are designed to pool resources and increase operational efficiencies, the cultural diversity of team members may create a longer learning curve for establishing effective processes than culturally homogeneous group. Managers and members of global teams are faced with the challenge of how to access and utilize individual member's strengths, while at the same time minimizing coordination losses from communication problems, language differences, varying work styles, and misunderstandings. The challenge in managing global teams effectively is to recognize underlying cultural causes of conflict, and to intervene in ways that both get the team back on track and empower its members to deal with future challenges themselves.

Global teams are formed to enhance the efficiency of an organization by making effective use of the diversity or viewpoints. A global team is a group of employees selected from two or more country (cultures) who are brought together to coordinate, develop, or manage same aspect of a firm's global operations. Cultures exist among people who share the same nationality, the same organizational affiliation, the same function or even the same gender. Members of the same culture share common views and they likely to interpret and evaluate situational events and management practices in similar ways. In contrast, members of different cultures are more likely to respond differently to the same event or managerial approach. Research on team composition suggests that homogenous teams ( all members from the same culture) are more satisfied and experience more positive reactions, while heterogeneous teams ( with multicultural members ) experience enhanced team creativity and breadth of solutions to a problem. Being composed of individuals from different cultures the multicultural teams provide solutions to problems which homogenous teams are unable to device. Multicultural teams provide an opportunity to integrate widely different social, 
cultural and business perspective into key decisions affecting the success of international operations.

\section{The benefit of using global teams}

Cultural diversity is a twin sword: if managed properly it can help an organization to enhance its performance, on the contrary if neglected cultural diversity can decrease the performance of the team. The benefit of using global teams are:

$>$ Since due to globalizations are in a continuous quest to tap the opportunities inherent in the different areas of the world, global teams enable organizations to address to the needs and demands of specific markets. Global teams can help organizations develop better relationship with the international customer.

$>$ Multinational corporations often create global research and development teams to benefit from site- specific scientific expertise that is not available in one location, but is spread around the world. Still other companies create global teams in specific functional areas, like sales and marketing, and then have representatives of that function from around the world collaborative in teams. This enables the organizations to benefit from a diversity of perspectives and services that can match or fulfill the needs of a global client, wherever that client might be located.

$>$ Global teams provide organizations with a variety and collection of viewpoints. Since members of a global team belong to different culture, each member of the multicultural team brings along with him a unique viewpoint and approach to the problem. "Diverse group of individuals should be expected to have a broad range of knowledge, expertise, and perspectives than homogenous group of individuals do" (Hoffman, 1961). Multicultural group 's performance is also better than homogenous groups because they have with them at their disposal a collection of different perspectives, as a result groups are exposed to new ways and methods to deal with problems and situations.

$>$ From manager's perspective, when people from diverse cultural backgrounds work in teams, they often provide a reasonable understanding about individual cultures and norms. However experience with diversity leads to a better control in managing employees. Companies competing in the global markets need to globally introduce innovative products, services and processes rapidly and effectively. As in the emerging knowledge economies many companies are forced to access globally dispersed technological and market knowledge to maintain their competitive advantage by developing an expert team of different cultures.

\section{Why Global Teams Fail}

Domestic teams and global teams are plagued by many of the same problems - misalignment of individual team members' goals, a dearth of the necessary knowledge and skills, and lack of clarity regarding team objectives. But global business teams face additional challenges resulting from differences in geography, language and culture. The difference between traditional team work in a single context and global teams work across multiple contexts are presented in Table 1.

Table 1. Differences in Context Between Traditional and Global Teams

\begin{tabular}{|l|l|}
\hline Traditional Teams Work in a Single Context & Global Teams Work Across Multiple Contexts \\
\hline Common physical location and work environment & $\begin{array}{l}\text { Multiple physical locations and work } \\
\text { environments }\end{array}$ \\
\hline Common national culture in a single geography & Multiple national cultures in multiple geographies \\
\hline Common economic and political conditions & $\begin{array}{l}\text { Multiple and dissimilar economic and political } \\
\text { conditions }\end{array}$ \\
\hline Native language speakers & Native and non-native language speakers \\
\hline
\end{tabular}




\begin{tabular}{|l|l|}
\hline Professional expertise and communication skills & $\begin{array}{l}\text { Cross-cultural competence and adaptability in } \\
\text { addition to professional expertise, communication } \\
\text { skills }\end{array}$ \\
\hline $\begin{array}{l}\text { Task is generally contained within organizational } \\
\text { and national boundaries }\end{array}$ & $\begin{array}{l}\text { Task generally involves crossing organizational } \\
\text { and national boundaries }\end{array}$ \\
\hline $\begin{array}{l}\text { Opportunity for frequent, face-to-face and } \\
\text { informal interactions and information sharing }\end{array}$ & $\begin{array}{l}\text { Opportunities for informal interaction are } \\
\text { infrequent and interaction is generally structured } \\
\text { and mediated by technology }\end{array}$ \\
\hline Work within a single time zone & Often work across multiple time zones \\
\hline
\end{tabular}

(Source: Gluesing J.C., Gibson C.B. Designing and Forming Global Teams, CEO Publication, 2003)

Teams can fail when they are unable to cultivate trust among their members or when they cannot break down often - formidable communication barriers. The challenge of managing global business teams are:

$>$ The inability to cultivate trust among team members. Trust is critical to the success of global business teams in that it encourages cooperation and minimizes unproductive conflict. Each member of a global teams brings a unique cognitive lens to the group. If harnessed effectively, the resulting diversity can yield significant synergies and produce a collective wisdom superior to that of any individual. Without mutual trust, however, team members may shy away from revealing their true benefits. The absence of trust is likely to turn a team's diversity into a liability rather than an asset. Global business teams are particularly prone to problems of trust. Among the many factors that determine how much trust people feel, three important ones are individual characteristics, quality of communication and the broader institutional context.

$>$ Communication barriers resulting from differences in geography, language and culture also can sabotage global business teams. Geographical barriers. With members living in different countries, separated by time zones and conflict schedules, arranging team meeting can pose logistical challenges. Undoubtedly, technology (e-mail, teleconferencing, videoconferencing) can enable members to work together despite geographical distance: but technology should be viewed as a complement to, not as a substitute for, team meetings. Face - to face meetings foster familiarity and trust - not easily established virtual meetings. When members cannot see one another's body language and direct experience one another's reactions, the emotional dimension critical to a team's success suffers. Language barriers. The inability to understand what another person is saying is always a potential barrier to communication in cross - cultural settings. If language barriers are not adequately addressed, the likelihood of creating an atmosphere conducive to candid sharing of different viewpoints / and hence conducive to achieving creative solutions - is greatly diminished.

$>$ Cultural barriers. Members of global business teams typically come from diverse cultures and, as a result, may bring different values, norms, assumption and patters of behavior individualistic and collectivistic cultural norm for decision making. National culture has a strong impact on people's values and hence behavior. Gert Hofstede's way to describe national cultures in five dimensions has proved to be useful for researchers.

- Power Distance: refers to the beliefs that people have about the appropriateness of either large or small differences in power and authority among the members of a group or society. In low power distance cultures, attempts are made to minimize inequality, people in subordinate positions find it easy to access people in superior positions, and equal rights are emphasized. In high power distance societies, power holders are entitled to privileges and power is considered a basic fact of societies.

- Uncertainty Avoidance: focused on the extent to which people are comfortable with uncertainty or ambiguity in the workplace. In low uncertainty avoidance societies, there is less emphasis on rules, the younger generation is considered more trusting, emotions are expressed rarely, and deviation is easily tolerated. In high uncertainty avoidance cultures, experts are valued, hard work is considered important, and a strong need for consensus is felt. 
- Individualism / Collectivism: this dimension is the extend to which needs and aspirations of individuals get priority and importance compared to needs of others and of collectivities. In the individualistic cultures, personal autonomy, freedom, individual achievement, and right to privacy are valued. On the other hand members belonging to a collectivistic culture emphasize the welfare of their fellows than themselves, according to them decision making should be a collective attempt.

- Masculinity / Femininity: this is the extend to which assertiveness, performance, independence, and role differentiation (by gender, or sex) are valued by societies. Members of masculine cultures tend to exhibit aggressiveness in pursuing their goals and place a high value on achievement, decisiveness and assertiveness. In feminine cultures, interdependence and relationships are important, roles are not clearly defined according to sex differences, and quality of life is important.

- Long term vs. Short term orientation: this dimension is concerned with the extent to which societies include a Long - Term Orientation towards tradition and change. People of a culture with long/term orientation believe that values hard work, personal sacrifice for future benefits, dedication to a cause, and personal thrift. The emphasis is on sacrifice so that future generations can prosper. Cultures with short - term orientation give more value to personal steadiness and stability. People with this orientation only live for the present.

\section{Develop Global Team}

There are four key design techniques that help create a supportive environment for global teams: clearly specify the task objective and align it with organizational strategic initiatives; make appropriate resources available; select team members who have the skills, abilities and experience to work in a global team, including the team leader if appropriate; and create a sense of urgency.

1. Clearly specify the task objective and align with organizational strategic initiatives. It is important to establish a clear task objective and to align the objective with organizational initiatives, whether those initiatives are tied to global efficiency, local responsiveness or organizational learning or knowledge creation. If team members do not know how their task fits with overall objectives as well as with their own priorities, it will be more difficult for them to commit and hence, to participate fully in the team's task. The more clearly and specifically managers can define the task, the greater the likelihood that teams with short life cycles and urgent deadlines meet with success. Organizational leaders who will have a stake in the outcome of the team's work should be identified early and should all participate in the task definition to achieve alignment across organizational boundaries. Some basic task boundaries and process guidelines can help teams begin their work with reduced complexity. Managers should provide the team a basic outline for their scope of work and offer some teaming templates and recommended processes that can team members can start with. Particularly if they are new to global teaming, team members need to begin their work with some minimal structure and then adapt it to their needs. Offering guidelines that can to help team members understand where decision authority lies and what their reporting relationships are helps to avoid the confusion that ambiguous reporting relationships can create. These boundaries are important even if the team members will be working together on a part-time basis or only for a short while. In fact, more structure may be necessary when teams will be of short duration and with tight deadlines since the team does not have time to create this structure themselves. In sum, as a first step in pre start-up organizational leaders can manage task complexity by taking four key steps:

- Provide the team with a well-defined, strategically aligned objective;

- Actively endorse the team's objective;

- Offer a minimal structure for the team's scope of work and some general process guidelines; 
- Give the team basic guidance regarding organizational responsibility and decisionauthority related to their objective.

2. Make resources available. Global teams are embedded not just in one, but in many contexts that may possess quite different systems of organizational support, including budgets, work processes, human resource policies and support people, such as facilitators, administrative support, and information technology tools and facilities. Incompatible or insufficient resources are a major source of complexity and frustration for global team collaboration. To manage this complexity before a team is formed, the appropriate stakeholders or managers should conduct a resource assessment to determine the state of available resources, including the degree of overlap in the type and availability of resources across organizational and country boundaries. If there is a great deal of disparity or imbalance, with "rich" and "poor" resources in different contexts, managers may want to invest in resources before the team begins or reallocate resources that are available elsewhere. In a globalized world, however, if the firm wants to remain competitive, investment in global collaboration support systems will eventually be necessary. While it is not always possible to level the playing field entirely, managers should attempt to secure as many resources as possible in advance of the team's formation, or specify a clear path to accessible resources, so that team members do not have to spend valuable time searching for essential support people, information or technology, or worse yet, become so frustrated they are unable to execute their objective.

There is one caveat about resources: while information technology is a critical resource for global teaming, the availability of technology resources is not sufficient for successful performance. Members must also be comfortable with the technology, and it should be reliable in each location where it is deployed. Simple technologies like email and audioconferencing may suffice, and constitute the best technology choices for teams, especially when time is short. Team members do not have time to learn new technology if they are under pressure. At start up, team members should be well acquainted with the technology and have enough "media dexterity" to use the technology effectively to avoid the technology downtime that can distract team members from their task. At the same time, technology use is a process of adaptation. Team members must be allowed to negotiate and come to a set of shared norms about how to communicate and which technology to rely on most heavily. In fact, the eventual performance of short-term teams working on high-stakes tasks is strongly influenced by members' ability to come to early agreement on communication processes. Ideally, they need to have a number of readily accessible communication channels that allow them to match their communication needs with the media available. In summary, managers can control resource complexity, especially the complexity that can result from incompatible or imbalanced human resource and information technology systems, if they keep these points in mind:

- Conduct a resource and information technology assessment prior to the start-up of the team;

- Make an investment decision to acquire or reallocate support resources if necessary, or if resources are not available, postpone the team start-up if possible;

- Specify for the team a path to available resources;

- It is management's job to make resources available to the team; however, the team should make the decision about the best match of resources and technology to match their needs as circumstances require and as team member skills, abilities and preferences are negotiated.

3. Select team members who have the skills, abilities and experience to work in a global team. Global team members need to be adept at working with task uncertainty, member diversity, and a variety of team situations. Team members too often are selected based only upon professional expertise or job roles alone, or upon their availability to do the technical work. Research indicates that employees tend to be more comfortable and effective in a global teaming situation if they are capable of performing the core tasks for their roles, are 
self-disciplined and goal-directed, are flexible, collaborative and willing to share and exchange information, and remain open to feedback. Global team members should be perceptive and receptive to differences in people and culture, ways of thinking, and alternative approaches to processes. They need to be capable of handling the uncertainty. They should also be committed and connected to the business and competent in using technology required for their roles. These skills, while desirable in many work settings in multinational corporations, are particularly crucial to the viability of global teamwork.

There are selections tools, such as the Global Personality Inventory (GPI), which is a measurement tool specifically developed for work-related use by psychologists working in or with global organizations. It was designed for applications such as pre-employment selection, developmental assessment, coaching, and succession management. Measures such as this one can help managers to select team members who can work well at the global level. The Cross-Cultural Adaptability Inventory is a self-assessment tool that can help team members determine the likelihood that they will adjust well to a global teaming situation. Team members can assess themselves on four dimensions that research has shown to be important in adapting to cross-cultural situations: flexibility-openness, emotional resilience, personal autonomy, and perceptual acuity. The instrument offers suggestions for what team members can do to increase their abilities on these dimensions as well.

It is particularly important to select people to be members of global teams who are capable intercultural communicators, because effective communication is especially critical for integrating diversity in global teams. Team members should be motivated to communicate with unalike individuals and be able to take on each other's perspectives so they can make correct interpretations of behavior, especially when they encounter difficulties.

In selecting people for work in global teams it is important to remember that cultural biases, especially those derived from national culture, can have marked effects on team performance. There are taken-for-granted assumptions in every culture about the desirable qualities of the global manager and about how a good team member behaves, with some particularly strong contrasts between Eastern and Western cultures in the criteria for what constitutes an effective team member. Even the most sophisticated global executives are subject to biased assessments of these criteria. It is necessary to get more than just a monocultural perspective on the selection criteria and to use differences of opinion as a way of exposing implicit biases.

When managers are designing a team for short-duration or temporary task work, it is especially important to select the right team members. Members who already know one another, who may have worked together well on previous projects and are comfortable with one another, are more likely to have some shared understanding of each other as people. A precondition for a fast start is enough of a shared reality among team members to enable effective communication without spending too much time surfacing differences and negotiating a shared resolution, especially when the differences have to do with how people relate to one another. There is also likely to be a foundation of trust and shared knowledge of each other's work habits if people have worked together previously. They do not have to spend time getting to know one another's working styles. Even if not all of the team members know each other, if a core group has had previous experience working together successfully, they can get off to a speedy start. If the team members do not know one another at all, it is possible for "swift trust" to develop and a "swift start" to occur if channels and norms for communication are pre-specified.

The leader plays a pivotal role in global teams. Effective leaders must manage the organizational, linguistic, cultural and physical distances that separate members, create severe communication barriers, impede the development of trust and contribute to the misalignment of members' goals. To maximize their chances of successful teaming outcomes, organizational leaders and managers should remember these key points when they are selecting people to work in global teams: 
- Team members should be selected for professional expertise and roles related to the task, but they should also be selected based on their ability to handle task uncertainty, to integrate diverse perspectives and work practices, and to adapt to a variety of team situations:

- Engage the help of human resource professionals who can use selection tools that will provide some measure of an individual's global competencies and also allow team members to assess their own level of comfort with a global team assignment.

- Be especially mindful to select members who are effective communicators, particularly interculturally.

- If at all possible, select team members who know one another or who have worked together well on previous assignments, especially if the team will have a short deadline and a high priority task.

4. Create a sense of urgency. Managers can maintain task focus, and reduce complexity if they structure the team to convey a sense of urgency. There is nothing like a deadline to help focus minds. Research indicates that tight deadlines can get a group moving. As with complexity and uncertainty, however, managers must be careful not to assign so much urgency that the members feel anxious about their ability to achieve. Pressure can push people to find solutions to differences and to come to agreement for the sake of protecting their mutual self-interest. A sense of urgency can come from environmental factors in the marketplace or in the organization, such as new competitive pressures, new requirements from higher level managers, poor business results, or pressure from a global customer everyone serves. Managers can convey a sense of urgency in the way they frame the goals for the team, by obtaining top level endorsement for the goals, by bringing the voice of a credible customer into the task rationale, or by making a good business case for the goals, such as demonstrating a large investment that may be at risk. However, it is important that managers realize that it may take multiple sources of evidence to achieve a shared sense of urgency. Understanding what is likely to appeal to team members' sense of urgency and then exerting positive pressure to engage in collaborative work are key to framing the goals to energize global teamwork.

In summary, managers can help team members align with their task objective by taking the following actions:

- Frame the objective as important to the organization by selecting credible sources to endorse the objective;

- Connect the team's objective to pressure from outside organizational boundaries, from competitors or customers in the marketplace;

- Provide deadlines;

- Connect the objective to people's careers or to rewards that will motivate participation.

Global business teams are ubiquitous throughout multinational corporations. But managing them effectively and steering them toward their intended goals is not easy.

\section{Bibliography}

1. Gluesing J. C, Gibson C. B.(2003), Designing and Forming Global Teams, CEO Publication,

2. Gibson, C. B., Building Multicultural Teams: Learning to Manage Homogeneity and Heterogeneity, Chapter appear in N.A. Boyacigiller, R.A. Goodman, and M.E. Phillips, Crossing Cultures: Insights from Master Teachers, Blackwell Publishing, 2004.

3. Govindarajan Vijay, Gupta Anil K, (2001) Building an Effective Global Business Team, Vol.42. No.4 